\title{
WhatsApp messenger, workload and satisfaction with work-life balance among employees of a Malaysian government office
}

\author{
Muhamad Khalil Omar*, Azzarina Zakaria, Zyasfitri Ismawati Awang Ismail \\ Faculty of Business and Management, Universiti Teknologi MARA, Selangor, Malaysia
}

\section{A R T I C LE IN F O}

\section{Article history}

Received 14 February 2017

Received in revised form

21 July 2017

Accepted 22 July 2017

\section{Keywords:}

Work-life balance

Workload

WhatsApp messenger

Government

\begin{abstract}
A B S T R A C T
This research was performed using cross-sectional survey with the participation by one hundred (100) respondents among staffs of a Malaysian government records and pensions office. This study comprised of four analyses: reliability analysis, descriptive analysis, Pearson's correlation analysis and multiple regression analysis to measure the relationships between independent and dependent variables. Surprisingly at the end of the study, the researchers found that while there were no significant effect of WhatsApp Messenger towards the employees' workload, WhatsApp Messenger had significant and positive effects towards employees' satisfaction with work-life balance, Thus, the information and findings of this study could help other researchers with their upcoming research on WhatsApp Messenger, workload and work-life balance. At the same time, practitioners, academics and policy makers would benefit from this research by identifying the factors that can determine the work-life balance among employees. The organization should also make reference of this study in getting a greater view on whether the current working pattern has affected the employees' work-life balance that later may affect their attitudes and productivity.
\end{abstract}

(C) 2017 The Authors. Published by IASE. This is an open access article under the CC BY-NC-ND license (http://creativecommons.org/licenses/by-nc-nd/4.0/).

\section{Introduction}

The increasing sophistication of communications in today's world has created a variety of applications such as messenger to interact with human beings irrespective of families, colleagues, employers and friends. These applications and the use of high-technology mobile have made people easy to communicate and sharing information without any limits.

Application messenger that mostly used by current employees is WhatsApp Messenger, i.e. an instant mobile messaging service for smart phones, founded in 2009. WhatsApp Messenger has now become one of the largest mobile messaging services in world with 1 billion active users as of February 2016, and the number keeps on increasing. Consequently, the usage of WhatsApp Messenger increased the workload among employees. For work matters, employer sometime gives urgent instructions via the WhatsApp Messenger that

\footnotetext{
* Corresponding Author.

Email Address: khalil.omar@salam.uitm.edu.my (M. K. Omar) https://doi.org/10.21833/ijaas.2017.09.015

2313-626X/C) 2017 The Authors. Published by IASE.

This is an open access article under the CC BY-NC-ND license

(http://creativecommons.org/licenses/by-nc-nd/4.0/)
}

requires employees to be alert, and always be ready about their task even at times when employees are not at their work.

As a result the employees felt that work updates and instructions using WhatsApp Messenger give them workload and distract their focus from other than work activities hence making them frustrated to handle. Although these situations were not faced by all employees but they felt that works had become the priority than their family, vacation, etc. Hence, the researchers wanted to identify the relationship of WhatsApp Messenger towards employees' workload and their work-life balance. Therefore, the objectives of this study are as follows:

- To identify the relationship between WhatsApp Messenger and employees' workload.

- To identify the relationship between WhatsApp Messenger and employees' satisfaction with worklife balance.

\section{Literature review}

Previous studies on work-life balance consider technology as one of the factor that has significant influence in work-life balance (Boswell and OlsonBuchanan, 2007; Orlikowski and Scott, 2008; Park 
and Jex, 2011). According to Robbins and Judge (2009), electronic communications include text messaging, video conferencing, networking software and internets services such as emails, web logs and etc. Information and Communication Technology (ICT) is the electronic system that is used for communication between individuals or groups, and the system allows for its users to not necessarily be present physically at the same location. To accommodate flexible working practices nowadays, ICT's capabilities were enhanced and expended greatly. This in turn allows workers to be able to complete their work at any time and location that is convenient for them (Grant et al., 2013). Researchers in work-life balance (WLB) studies view mobile technologies as very important, since these technologies are the medium that allows for the assimilation between personal life and work to happen in the first place (Duxbury and Smart 2011; Golden and Geisler, 2007). Thus, with such technology usage among employees and employers, we may find two types of workers; the type of workers that brings their non-work lives into their workplace, and the workers that tried to separate their non-work lives with work. However, using ICTs has also been reported to cause confusion of the boundaries between work and non-work. The confusion often leads to a situation where work may creep into the territory of a worker's private lives. According to Fleck et al. (2015) ICT's can lead to invasion from one role to another, often with negative effects, hence causing heavier workload and work-life imbalance. According to Omar and Zakaria (2015), work-life balance (WLB) is defined as a person trying to equally prioritize their work, individual lives, family, and responsibilities to their community. Therefore, WLB can be generally defined as the extent to which individuals achieved equal levels of involvement and satisfaction in work and personal life. There are practical advantages in using satisfaction with work-life balance (WLB) as an approach to tackle the concerns about work-life balance (Omar and Zakaria, 2015). The analysis of Duxbury and Smart's (2011) survey on a Canadian sample found that $70 \%$ of the professional employees felt that mobile technology had increased their workloads, and $50 \%$ felt that mobile technology increased the amount of stress they are under. However, $49 \%$ of the sample did not feel that mobile technology affected their ability to balance work and family. Goh et al. (2015) claimed that there is no direct effect between workload and life satisfaction. His research findings recommend that individuals should not rate their life satisfaction as poorly and claimed that it is due to their high job demands, since their life satisfaction and workload may have other links that are influenced by need of fulfillment and challenge.

\section{Methodology}

Quantitative cross-sectional method using survey questionnaire is used in this study to identify the relationship between WhatsApp Messenger usage, workload and satisfaction with work-life balance. Descriptive method is also being used in this research to identify the characteristics of the respondents; for example age, gender, education and so on that were gathered using frequency analysis. The researchers used standardized Likert scale for all variables in this study ranging from $1=$ 'Strongly Disagree', 2= 'Disagree', 3= 'Neither Agree nor Disagree', 4= 'Agree' and $5=$ 'Strongly Agree'. A set of questionnaire with dual languages (English language and Bahasa Melayu) was distributed to one hundred (100) respondents as the main instrument for the data collection. The target respondent for this research was the individual employees in one of Malaysian government office doing records and pensions administration. The validated instruments from prior researchers were used in this study, i.e. WhatsApp Messenger has been adopted from Cho et al. (2005) and Quan-Haase et al. (2005) workload has been adopted from De Bruin and Taylor (2006), while satisfaction with work-life balance has been adopted from Omar and Zakaria (2015). Non probability sampling technique of quota sampling was used in this study. Since one of the researchers is currently working in the surveyed organization, the selection of participant within employees in the organization would certainly make it easier for the researcher to monitor the survey process. Nonetheless, the participation of respondents was made voluntarily and all information was treated as private and confidential. The collected data were coded and analyzed using the SPSS program version 17.

\section{Results and discussion}

Based on 100 respondents of this study, the highest frequency of gender were female with 55\% higher than male of $45 \%$. The highest frequency of age was ranging from 31 to 35 years old with $33 \%$. This was followed by age ranging from 26 to 30 years old with $22 \%$, age ranging from 36 to 40 years old with $19 \%$, age ranging from 20 to 25 years old with $16 \%$ and lastly $10 \%$ for the age above 40 years old. On top of that, $88 \%$ respondents were Malay, $9 \%$ respondents were Indian and 3\% respondents were others. No respondents among Chinese ethnicity since there were nil Chinese employees in the surveyed organization. In terms of marital status, $76 \%$ respondents were married, $21 \%$ respondents were single and $3 \%$ were others which may be a divorce or widow. The majority of the respondents have 1 to 3 children living with them i.e. the highest percentage of $56 \%$. The second highest percentage was no children living with the respondents i.e. the percentage of $31 \%$. The lowest percentage was 13\% where the respondents have 4 to 6 children living with them. No respondents that have above 6 children. On the other hand, most of the respondents were SPM leavers with $65 \%$. These were followed by Diploma holders with 17\%, STPM/Certificate with $10 \%$ and lastly Degree holders with $8 \%$. The highest 
percentage of respondents' monthly income was $37 \%$ with the range income of RM 2,001 to RM 3,000 . The second highest was $34 \%$ with the range income of RM 1,001 to RM 2,000. Next was 23\% with the range income of RM 3,001 to RM 4,000 and the lowest was $6 \%$ with the range of above RM 4,000. On top of that, most of the respondents had worked at the organization between 1 to 10 years i.e. the highest percentage of $48 \%$. The rest were 11 to 20 years with $42 \%$, above 20 years with $9 \%$ and lastly $1 \%$ for those who had worked for less than 1 year.
Table 1 showed that the highest mean was 3.88 represent "I often use WhatsApp Messenger to contact other people for my work". For the lowest mean by 3.24 that represent "I frequently using WhatsApp Messenger to share files/information in my daily work. The overall mean for this variable is 3.55 that show the usage of WhatsApp Messenger among employees at the surveyed organization was quite high. Additionally, it can be seen that WhatsApp Messenger has the highest reliability with Cronbach's Alpha of 0.905 .

Table 1: Descriptive and Reliability Analysis of WhatsApp Messenger

\begin{tabular}{|c|c|c|}
\hline Items & Mean & Std. Deviation \\
\hline I often use WhatsApp Messenger to contact other people for my work & 3.88 & .72864 \\
\hline I regularly use WhatsApp Messenger to communicate with colleagues in my daily work & 3.73 & .83913 \\
\hline I frequently using WhatsApp Messenger to ask questions in my daily work & 3.56 & .83267 \\
\hline I frequently using WhatsApp Messenger to answer questions in my daily work & 3.55 & .83333 \\
\hline I frequently using WhatsApp Messenger to share files/information in my daily work & 3.24 & .91143 \\
\hline I frequently using WhatsApp Messenger for work-related socialization in my daily work & 3.34 & .87870 \\
\hline Overall & 3.55 & .69126 \\
\hline Cronbach's Alpha & \multicolumn{2}{|c|}{0.905} \\
\hline
\end{tabular}

Referring to Table 2, the lowest mean was 2.61 that represent "I am so busy and find it difficult to concentrate on the job in front of me". On the other hand, the highest mean was 3.23 represent two statements that have the similar mean i.e. "I work more than 8 hours a day" and "I have to work very fast". The overall mean for workload variable was 2.96 that showed the moderate level of workload among employees of the surveyed organization. Additionally, it can be seen that workload has the lowest reliability with Cronbach's Alpha of 0.811 thus the result indicated a good reliability for workload variable.

Referring to Table 3, the highest mean was 3.75 with two statements that appear in same result. "I am satisfied with the opportunity I have to perform my job well and yet be able to perform non-work related duties adequately" and "I am satisfied with how well my work life and my non-work life fit together". On the other hand, the lowest mean was 3.62 which three statements give the similar result i.e "I am successful in balancing my work and nonwork life", "I am satisfied with the way I divide my time between work and non-work life" and lastly "I am satisfied with how well my work life and my nonwork life fit together". The overall mean for satisfaction with work-life balance variable was 3.67 that showed the level of satisfaction with work-life balance among employees of the surveyed organization was quite high. Additionally, this variable has a very good reliability with Cronbach's Alpha of 0.898 .

Table 2: Descriptive and Reliability Analysis of Workload

\begin{tabular}{|c|c|c|}
\hline & Mean & Std. Deviation \\
\hline I feel that there are too many deadlines in my work that are difficult to meet & 2.93 & .86754 \\
\hline I work more than 8 hours a day & 3.23 & .97292 \\
\hline I work for long hours even on holidays & 2.83 & .96457 \\
\hline I have to work very fast & 3.23 & .87450 \\
\hline My daily activities affected because of workload (i.e, exercise, eating time and sleeping time) & 2.92 & .90654 \\
\hline I have unrealistic time pressure & 2.96 & .85185 \\
\hline I am so busy and find it difficult to concentrate on the job in front of me & 2.61 & .80271 \\
\hline Overall & 2.96 & .61195 \\
\hline Cronbach's Alpha & \multicolumn{2}{|c|}{0.811} \\
\hline
\end{tabular}

Table 3: Descriptive and reliability analysis of satisfaction with work-life balance

\begin{tabular}{|c|c|c|}
\hline & Mean & sta. Deviation \\
\hline I am successful in balancing my work and non-work life & 3.62 & .74914 \\
\hline I am satisfied with the balance between my job and non-work life & 3.69 & 64659 \\
\hline I am satisfied with the way I divide my time between work and non-work life & 3.62 & .70754 \\
\hline I am satisfied with the way I divide my attention between work and non-work life & 3.64 & .74563 \\
\hline I am satisfied with how well my work life and my non-work life fit together & 3.62 & .67838 \\
\hline I am satisfied with my ability to balance the needs of my job with those of my non-work life & 3.75 & .57516 \\
\hline $\begin{array}{l}\text { I am satisfied with the opportunity I have to perform my job well and yet be able to perform non-work } \\
\text { related duties adequately }\end{array}$ & 3.75 & .57516 \\
\hline Overall & 3.67 & .52859 \\
\hline Cronbach's Alpha & \multicolumn{2}{|c|}{0.898} \\
\hline
\end{tabular}

The Pearson correlation matrix obtained for four variables in this study is shown in Table 4. Referring to the results, it was discovered that the WhatsApp Messenger was positively correlated with workload (0.134) and satisfaction with work-life balance
(0.294). The correlations were all in the expected direction however only correlation between WhatsApp Messenger and satisfaction with work-life balance that was significant. On the other hand, the workload was negatively correlated with satisfaction 
with work-life balance $(-0.108)$. However the correlation was not significant. Therefore, it can be concluded that only WhatsApp Messenger had the positive association with employees' satisfaction with work-life balance.

Table 4: Correlation analysis

\begin{tabular}{cccc}
\hline Variables & WhatsApp Messenger & Workload & Satisfaction with Work-Life Balance \\
\hline WhatsApp Messenger & 1 & & \\
Workload & .134 & 1 & 1 \\
Satisfaction with Work-Life Balance & $.294^{* *}$ & -.108 & 108 (2-tailed); ${ }^{*}$ Correlation is significant at the 0.05 level (2-tailed)
\end{tabular}

Table 5 describes the result for multiple regression analysis performed for both dependent variables i.e. workload and satisfaction with worklife balance proposed in this study. Based on Table 5, the multiple regression models with WhatsApp Messenger as the independent variable produced $\mathrm{R}$ square of 0.02 for workload and 0.09 for satisfaction with work-life balance.

Table 5: Regression Analysis

\begin{tabular}{ccc}
\hline \multirow{2}{*}{ Independent variable } & \multicolumn{2}{c}{ Dependent variables $(\beta)$} \\
\cline { 2 - 3 } & Workload & Satisfaction with Work-Life Balance \\
WhatsApp Messenger & .13 & $0.29^{*}$ \\
& & $9.26^{*}$ \\
F value & 1.79 & 0.09 \\
$\mathrm{R}^{2}$ & .02 & 0.08 \\
Adjusted R & .01 &
\end{tabular}

Therefore, R Square represented that there was only $2 \%$ of the variation in employees' workload and $9 \%$ of the variation in the employees' satisfaction with work-life balance can be explained by the usage of WhatsApp Messenger. Additionally, Table 5 also shows that only model for dependent variable of satisfaction work-life balance was fit, with the significant values that was less than $0.05(\mathrm{p}<0.05)$ and $F$ value of 9.26. Through to that, it was found that WhatsApp Messenger was significantly and positively affecting satisfaction with work-life balance, with $\mathrm{p}<0.05$ i.e. $\beta=0.29$, while no significant relationship/effect was found between WhatsApp Messenger and workload. Thus, it is concluded that the usage of WhatsApp Messenger has significant positive effect towards employees' satisfaction with work-life balance and there was no significant effect of WhatsApp Messenger usage towards employees' workload.

\section{Conclusion}

The main objective of this research was to identify whether WhatsApp Messenger usage shall affects employees' workload and their satisfaction with work-life balance. Based on a sample from 100 employees working in a Malaysian records and pensions administration office, the result of this research guides the researchers to answer two research objectives that the researchers wanted to achieve. In conclusion, one hypothesis was accepted i.e. $\mathrm{H} 2$ and one hypothesis was rejected i.e. H1. The significant positive relationship between WhatsApp Messenger and satisfaction with work-life balance as dependent variable were identified using multiple regression analysis.
Therefore this study concludes that WhatsApp Messenger is positively predicting work-life balance among employees. This study suggests that the employees who are using WhatsApp Messenger can be better in balancing the demands of their work and non-work lives. This maybe because the usage of WhatsApp Messenger enables them to communicate and be updated about their work although there were might be not in the office doing other non-work activities. The results of this study supports the notion by Duxbury and Smart (2011) who found their respondents did not feel that mobile technology affected their ability to balance work and family. Therefore, as an employer flexible work options should be introduced and the usage of WhatsApp Messenger among the employees must be considered in work activities.

On the other hand, this study also found that there no significant effect of the usage of WhatsApp Messenger towards employees' workload. This result shows thus be in line with the earlier findings of this study that the usage of WhatsApp Messenger helps employees to better balance their work and life, hence by using WhatsApp Messenger employee should not feel much workload as the messaging system shall makes the job much easier in terms of communication, sharing information, files, workrelated socialization and many more. In reality, the actual workloads normally being instructed formally in office setting using formal communication channel other than WhatsApp Messenger. The result of this study therefore was in contrary to Duxbury and Smart (2011)'s study who found majority of their respondents felt that mobile technology had increased their workloads.

Whilst this study only discussed WhatsApp Messenger as the only independent variable that 
affect employees' workload and satisfaction with work-life balance, it is recommended that future research need to include other factors that affect employees' workload and work-life balance or using other type of analysis such as Structural Equation Modeling (SEM) that can test all these variables simultaneously. For practitioners, it is suggested that employers should give any instructions to their employees in a proper timeline so that they can manage their work time wisely to complete the job as soon as they received them without interfering into their non-work life.

\section{Acknowledgment}

This research is funded under the Research Acculturation Grant Scheme from Ministry of Higher Education Malaysia. This research is also supported by the Universiti Teknologi MARA, Shah Alam, Malaysia.

\section{References}

Boswell WR and Olson-Buchanan JB (2007). The use of communication technologies after hours: The role of work attitudes and work-life conflict. Journal of Management, 33(4): 592-610.

Cho HK, Trier M, and Kim E (2005). The use of instant messaging in working relationship development: A case study. Journal of Computer-Mediated Communication, 10(4). https://doi.org/ 10.1111/j.1083-6101.2005.tb00280.x

De Bruin GP and Taylor N (2006). Development of the sources of work stress inventory. South African Journal of Psychology, 35: 748-765.

Duxbury L and Smart R (2011). The "myth of separate worlds": An exploration of how mobile technology has redefined work-life balance. In: Kaiser S, Ringlstetter MJ, Eikhof DR, and Cunha MP (Eds.), Creating balance? International perspectives on the work-life integration of professionals: 269-284. Springer Berlin Heidelberg, Heidelberg, Germany.

Fleck R, Cox A, and Robinson R (2015). Balancing boundaries: Using multiple devices to manage work-life balance. In the $33^{\text {rd }}$ Annual ACM Conference on Human Factors in Computing Systems, ACM, Seoul, Republic of Korea: 3985-3988. https://doi.org/10.1145/2702123.2702386

Goh Z, Ilies R, and Wilson KS (2015). Supportive supervisors improve employees daily lives: The role supervisors play in the impact of daily workload on life satisfaction via workfamily conflict. Journal of Vocational Behavior, 89: 65-73.

Golden A and Geisler C (2007). Work-life boundary management and the personal digital assistant. Human Relations, 60(3): 519-551.

Grant CA, Wallace LM, and Spurgeon PC (2013). An exploration of the psychological factors affecting remote e-worker's job effectiveness, well-being and work-life balance. Employee Relations, 35(5): 527-546.

Omar MK and Zakaria A (2015). Conseptualising work-life balance: Extension of work-family balance. Advanced Science Letters, 21(6): 2155-2158.

Orlikowski WJ and Scott SV (2008). Sociomateriality: Challenging the separation of technology, work and organization. The Academy of Management Annals, 2(1): 433-474.

Park Y and Jex SM (2011). Work-home boundary management using communication and information technology. International Journal of Stress Management, 18(2): 133-152.

Quan-Haase A, Cothrel J, and Wellman B (2005). Instant messaging for collaboration: A case study of a high-tech firm. Journal of Computer-Mediated Communication, 10(4). https://doi.org/10.1111/j.1083-6101.2005.tb00276.x

Robbins P and Judge TA (2009). Organizational behavior. Pearson Prentice Hall, Upper Saddle River, USA. 